\title{
ACERCA DE LAS COSAS QUE SE DAN, DE LAS COSAS QUE SE VENDEN Y DE LAS QUE NO HAY QUE VENDER NI DAR SINO QUE HAY QUE GUARDAR. UNA REEVALUACIÓN CRÍTICA DEL ENSAYO SOBRE EL DON DE MARCEL MAUSS
}

\author{
pot \\ MAURICE GODELIER
}

EHESS-París

RESUMEN: Este artículo evalua el papel y la importancia del don en el funcionamiento de las distintas culturas $y$ en la constitución de las relaciones sociales. Para ello, se parte de una reflexión sobre un texto ineludible, el Essai sur le Don de Marcel Mauss publicado en 1921. La perspectiva de este trabajo, a través de la discusión de las tesis de Mauss a la luz de la nueva bibliografía antropológica, se centra en el análisis de las cosas que se donan o las que se venden a partir de las cosas que se deben conservar, sobre todo los objetos sagrados. Se incorpora una nueva discusión: La de las cosas inalienables.

Palabras Clave: Antropología. Marcel Mauss. Don-contradon. Dones agonísticos. Dones no agonísticos. Propiedad. Inalienabilidad. Objetos preciosos. Objetos sagrados.

ABSTRACT: This article apraises the importance of gift on different cultures and its role in the formation of social relations. In this connection the starting point is a necessary reflection on the seminal work by Marcel Mauss, L'Essai sur le Don, publisbed in 1920. A discussion of Mauss' thesis based on recent antbropological bibliography, brings to light the study of things that must be kept, particulary sacred objects. A new discussion is proposed on inalienable tbings.

KEY WORDS: Anthropology. Marcel Mauss. Gift-countergift. Agonistic gifts. Non-agonistic gifts. Property. Inalienability. Valuable objects. Sacred objects. 
Nuestro objetivo común, de historiadores o antropologos, es analizar y comprender los diferentes modos de vida y de pensamiento inventados por la humanidad en su historia. Se trata de descubrir, en colaboración con los demás especialistas de las ciencias sociales, las razones de la aparición, de la conservación y de la desaparición de las diferentes formas de sociedad que la humanidad produjo y sigue produciendo. El hombre no vive en sociedad como los otros animales sociales, produce sociedad para vivir. Pero, observar, vivir con los demás, dialogar con ellos, observar lo que hacen, oir lo que dicen, comprender sus silencios, no significa identificarse totalmente con el otro, hacer de su verdad la única verdad, como si cada uno de nosotros ignorase las distancias que existen entre principios y prácticas, palabras y actos, como si no se supiera que todo orden social debe legitimarse para perpetuarse y que en ese trabajo de justificación muchos aspectos del funcionamiento real de la sociedad son ocultados, negados o disfrazados, transfigurados.

No olvidemos que no estudiamos objetos sino que tratamos de comprender cómo los seres humanos producen entre sí relaciones que tienen sentido para ellos, relaciones que por lo general se esfuerzan en reproducir.

Para construir una sociedad es necesario que una cierta cantidad de individuos y de grupos se reconozcan una identidad común, estén unidos por relaciones de dependencia material, política, simbólica que hagan que cada uno, hasta cierto punto, contribuya a reproducir a los otros y dependa de los otros para reproducirse, así como también contribuyen a producir un todo que los contiene y que los supera a cada uno por separado. Pero ello no significa que por el juego, por la naturaleza misma de esas relaciones de dependencia recíproca, esos individuos y esos grupos pertenecientes a una misma sociedad no se encuentren divididos entre sí por intereses opuestos y que en ciertos contextos no se opongan violentamente unos a otros.

Las contradicciones y los conflictos forman parte del funcionamiento normal de las sociedades. Y es evidente que no todas las contradicciones se originan en el seno de los grupos sociales sino también fuera de ellos, en las relaciones de fuerza y de dominación que se instauran entre las sociedades, como es el caso actualmente, de manera espectacular, con la expansión y la dominación mundial del sistema económico y social nacido en Occidente desde hace cuatro siglos, es decir del sistema capitalista.

Precisamente en ese contexto, a partir de los países centrales se difunde en el mundo entero la idea de que "todo es vendible» - Everytbing for sale-. Por esta razón mi objetivo es reexaminar el lugar del don en las diferentes culturas y mostrar que incluso en las sociedades en las cuales la economía de mercado está más desarrollada existen realidades esenciales que están más allá del mercado.

Evidentemente, al elegir analizar el don, me sitúo en el seno mismo de la antropología y tengo que remitirme a uno de los grandes momentos de esa historia y a un texto ineludible, el Essai sur le Don, de Marcel Mauss publicado 
en 1921 que hizo célebre a su autor' ${ }^{1}$. Recordemos el contexto de la composición del Ensayo. Se escribe apenas unos años después del final de la Primera Guerra Mundial, conflicto en el que Mauss había perdido a la mitad de sus amigos, y de la victoria de la revolución bolchevique en Rusia. Siendo socialista, había sostenido a Jean Jaurès, uno de los jefes del movimiento socialista, asesinado por haberse opuesto a esa guerra. Mauss, famoso universitario, escribía cada semana en el diario popular L'Humanité. Después de la guerra había visitado Rusia, donde se edificaba el poder comunista, y a su regreso se había convertido en opositor al bolchevismo por dos razones: por queter construir una economía que prescindiera del mercado y por recurrir sistemáticamente a la violencia para transformar la sociedad ${ }^{2}$. Pero en el Ensayo sobre el Don, Mauss critica sobre todo al liberalismo, no aceptando que la sociedad se encierre cada vez más en lo que llama «la fría razón del comerciante, del banquero y del capitalista» ${ }^{3}$. A modo de precursor diseña, en 1921, quince años antes de que el Frente Popular se imponga en Francia en 1936, un programa «socialdemócrata" en el que pide que el Estado otorgue a los que trabajan la ayuda material y la protección social que el salario no ofrece. Pero Mauss demanda también a los ricos y a los poderosos que muestren la misma generosidad interesada practicada por los jefes melanesios o los nobles Kwakiutl y que habían igualmente llevado a cabo los jefes celtas o germánicos en el pasado europeo. Porque, después de siglos de cristianismo, pensaba que la "caridad es todavía humillante para quien la recibe».

Hoy, de manera paradójica se retorna a la caridad y de nuevo el don vuelve a ser socialmente necesario. En los países más ricos del planeta, los que están en el centro del sistema mundial capitalista, día tras día se excluye de la economía a millones de personas. En estas sociedades en las cuales ganar dinero es la condición sine qua non de la existencia material y social de cada uno, en las que las solidaridades familiares o comunitarias se reducen o desaparecen, en las que el individuo se halla aislado por la sociedad misma, estar excluído de la economía significa estar prácticamente excluído de la sociedad. El Estado, que en Europa tenía un papel importante en la redistribución de las riquezas, toma sus distancias y deja, como se dice, decidir al mercado dando a cada uno según sus medios - financieros- la educación, la salud, la protección social, etc. En este nuevo contexto, un renovado interés por la obra de Marcel Mauss se manifestó hace algunos años originando numerosas conferencias y publicaciones.

\footnotetext{
1 Mauss, Marcel, «Essai sur le don. Forme et raison de l'échange dans les sociétés archaïques", en L'Année sociologique, nouvelle série, 1, 1925, y en id. Sociologie et Anthropologie, París, 1950 (trad. castellana, «Ensayo sobre los dones. Motivo y formas del cambio en las sociedades primitivasm, Sociologia y Antropologia, Madrid, 1971, pp. 153-263. Las reflexiones sobre esta obra se han hecho en extenso en Godelier, Maurice, L'énigme du don, París, 1996 (trad. Barcelona, 1998).

2 Fournier, Marcel, Marcel Mauss, París, 1994, pp. 417 y sigs.

3 Mauss, Marcel, lbid., p. 270.
} 
Hacemos una relectura de Mauss por cierto, pero no un retorno a Mauss porque, como lo veremos, en su obra muchos problemas quedaron sin respuesta y muchos hechos mencionados no fueron cuestionados ni por él ni por sus comentadores, entre los cuales figura en primer lugar Lévi-Strauss, quien escribió en 1950 una célebre introducción a la obra de Mauss, a manera de un primer "Manifiesto del Estructuralismo»". Entre estos hechos, hay uno mencionado por Mauss pero del que éste no extrae las consecuencias posibles. Se trata del hecho de que, entre los indios Kwakiutl y sus vecinos de la costa noroeste de América del Norte, los objetos más preciosos eran las célebres piezas de cobre que jamás entraban a formar parte de los potlatchs. Esas piezas de cobre se consideraban como sagradas y estaban inmobilizadas en los tesoros de los clanes y de las tribus. En otras palabras, al lado de los objetos preciosos que se pueden dar e incluso vender, existía otra categoría de objetos, los objetos sagrados, que había que conservar. El análisis de este hecho no fue realizado ni por Mauss ni por Lévi-Strauss, para quien toda vida social es intercambio - de mujeres, de bienes y de palabras-, intercambios que son los fundamentos de la economía y de la cultura.

\section{Para Mauss ¿Qué cosa es un don?}

Es un acto que al mismo tiempo instaura una relación doble entre el donante y el receptor. Dar es compartir voluntariamente lo que se tiene o lo que uno es. Un don forzado no es un don. El don voluntario aproxima al donante y al receptor y por ser voluntario crea una deuda a quién lo recibe, es decir, genera las obligaciones de recibir y de devolver o de volver a dar a su vez. Por lo tanto el don produce dos cosas al mismo tiempo, acerca y pone ambas partes a distancia. Instaura una disimetría, una jerarquía, entre el que da y el que recibe, puesto que, para que haya don, es necesario que lo dado sea aceptado. Desde Mauss se instaura como principio de análisis el hecho de que el don no es un acto que pueda ser estudiado aisladamente, sino que forma parte de un conjunto que nace del encadenamiento de tres obligaciones, la de dar, la de aceptar el don y la de devolver cuando uno aceptó.

Lévi-Strauss vió en Mauss el precursor del estructuralismo, es decir de sí mismo, por haber planteado el don como el primer eslabón de un encadenamiento de actos cuya estructura global tenía que ser analizada. Solamente precursor, pues según Lévi-Strauss, desgraciadamente Mauss había abandonado en el resto de su Ensayo sobre el Don los principios metodológicos propuestos al considerar como una explicación científica de la obligación de «devolver» una ideología indígena particular. Una ideología que se encuentra en los discursos del sabio Tamati Ranaipiri, de la tribu de los ngati-raukawa, quien había con-

4 Levi-STrauss, Claude, «Introduction à l'oeuvre de Mauss» en Saciologie et Antbrapologie, ed. cir. 
tado al etnólogo Elsdon Best las creencias de los Maori en la existencia de un espíritu (bau) en el objeto dado, espíritu que obligaría a quien recibe a devolver el objeto dado o algo equivalente a lo que se lo entregó (estos propósitos fueron recogidos por Elsdon Best en 1909). En resumen, según Lévi-Strauss, Mauss se dejó "engañar" por una ideología indígena, compleja y sutil, según éls. No era, sin embargo, la primera vez que un etnólogo caía en tal trampa.

Existe efectivamente una falla en Mauss, y en ella se introdujo Lévi-Strauss, proponiendo otra explicación de las nociones de bau o de mana o de manitu que interpreta como ejemplos de «significantes puros» o de «significantes vagos» en la medida en que están "vacíos de sentido". Según Lévi-Strauss, cuando el espíritu humano no puede explicarse las cosas, inventa conceptos vacíos que expresan directamente las estructuras inconscientes del espíritu y son la prueba del origen simbólico de la sociedad. De hecho, las nociones de bau, mana o manitu demostrarían la supremacía del lenguaje, de lo simbólico sobre lo imaginario, y a su vez la supremacía de lo simbólico sobre lo real. Incluso en el límite, los símbolos serían más reales que las realidades que simbolizan. Veremos, sin embargo, que existen otras explicaciones posibles para estos conceptos y que si hubiera que elegir una prioridad sería más bien la de lo imaginario sobre lo simbólico que a la inversa. Porque los objetos sagrados y los objetos preciosos son ante todo sujeto de creencia cuya naturaleza es imaginaria antes de ser simbólica, puesto que las creencias conciernen a la naturaleza y a la fuente del poder y de la riqueza que en gran parte son realidades imaginarias. Las caracolas intercambiadas para obtener una mujer o entregadas para compensar la muerte de un guerrero aparecen como sustitutos de seres humanos y son como equivalentes imaginarios de la vida.

Pero, ¿dónde se encuentra la falla en Mauss? Éste había dado razones sociológicas para explicar las dos primeras obligaciones, es decir, la de dar y la de aceptar los dones. Según él, uno está obligado a dar porque el dar obliga, y uno está obligado a aceptar, porque rechazar un don es quizás entrar en conflicto con el que lo ofrece. Pero ćpor qué cuando un don es aceptado es necesario devolverlo? Mauss propuso una explicación que reposaba principalmente en razones ideológicas, es decir en creencias místico-religiosas. Lo que llevaría a quien lo recibió a devolver un don sería una fuerza, un "espíritu» presente en el objeto recibido y que lo obligaría a volver a manos de su primer propietario. Pero, ¿de qué espíritu se trata? Leyendo cuidadosamente a Mauss parecería que a sus ojos los objetos están habitados no por uno sino por dos espíritus. Ante todo, el de quién lo poseyó primero y luego lo donó. De alguna manera, es el donante quien se encuentra presente en la cosa dada. Además el objeto en sí poseería un alma y sería como una persona que tiene el poder de actuar sobre otras personas. Retomando por su cuenta estas creencias maoríes, Mauss quería demostrar

5 Ibid., p. XXXVIII: «¿No nos hallamos ante uno de esos casos, no tan raros por otra parte, en que el etnólogo se deja mistificar por el indígena?». 
que el objeto dado no estaba realmente alienado, sino seguía unido a su propietario, y por lo tanto, paradójicamente, era a la vez inalienable y alienado.

¿Cómo explicar este dualismo? Lévi-Strauss apelaba a las estructuras inconscientes del espíritu, mientras que Mauss a las creencias conscientes de las sociedades. Quizá sea otra la explicación y el dualismo implícito en el objeto donado podría encontrarse en el hecho de que lo rigen dos principios del derecho: un derecho inalienable de propiedad y un derecho de uso alienable. Cuando se da un objeto, lo que se conserva es la propiedad, lo que se cede es el derecho de utilización para otros dones pero no para otros usos. Esta interpretación es la que proponen los habitantes de las islas Trobriand para explicar el funcionamiento de su sistema de intercambio ceremonial, el famoso kula que le sirvió a Mauss como ejemplo melanesio simétrico del potlatch americano. Desgraciadamente, esta explicación del mecanismo del kula no había sido descubierta por Malinowski y Mauss no podía conocerla. La debemos a los recientes trabajos de Annette Weiner y de Frederick Damon quienes a partir de la década de 1970 trabajaron en las islas Trobriand y en la isla Woodlark respectivamente ${ }^{6}$. Se trata de dos puntos esenciales del Kula-ring, el conjunto de rutas de intercambio que unen una serie de islas y de sociedades de la región del Massim en Nueva-Guinea.

\section{LOS DONES COMO PRESTACIONES TOTALES}

Tenemos que precisar antes de proseguir cuales son los dones que interesaron a Mauss y que fueron por él analizados. Son los que denomina «prestaciones totales», que no son dones individuales sino que implican a grupos o personas en tanto que representantes de esos grupos. Mauss no se interesa por los dones que un amigo hace a otro amigo, tampoco le interesa la representación imaginaria del don que un dios puede hacer de su vida para salvar a la humanidad. Le interesan los dones que son socialmente necesarios para producir y reproducir las relaciones sociales, el tejido de una sociedad, las condiciones sociales de la existencia de cada uno en una sociedad determinada. Como ejemplo de estos dones menciona los dones de mujeres entre clanes, los ritos cumplidos por una mitad en provecho de otra mitad, etc. Llama «totales» a estas prestaciones y la palabra designa para él dos cosas distintas. La primera, que el don sea un acto con múltiples dimensiones, de carácter económico, político, religio-

- WeINER, Annece, Women of Value, Men of Renown: New Pespectives in Trabriand Exchange, Austin-Texas, 1976; Idem, "Plus précieux que l'or:relations et échanges entre hommes et femmes dans les sociétés d'Océanie», Annales (E.S.C.), 2 (1992), pp. 222-245; Idem, Inalienable Porsessions: The Paradox of Keeping while Giving, Berkeley, 1992; DAMON, Frederick, «Representation and Experience in Kula and Western Exchange Spheres (Or, Billy)», Research in Economic Antbropology, 14 (1993), pp. 235-254; Idem, «The Problem of the Kula in Woodlark Island: Expansion, Accumulation and Over-Production», Ethnos, 3-4 (1995), pp. 176-201.

Hüpania, LX/1, núm. 204 (2000) 11-26 
so, artístico, es decir con la capacidad de condensar en sí mismo muchos aspectos de la sociedad. La segunda, que el don, al arrastrar "contradones" que movilizan las riquezas y la energía de numerosos grupos e individuos, ponga en movimiento a toda la sociedad y se presente como un mecanismo y un momento esencial en su reproducción?. Mauss distinguía además dos tipos de prestaciones totales, distinción que fue olvidada más tarde: unas, que llama «no agonísticas" y otras «agonísticas" (del griego agon, combate). Antes de analizar estas distinciones y las lógicas propias a estos tipos de dones hay que recordar que Mauss privilegió en su libro el análisis de los dones competitivos a los que designó de modo general con una palabra de la lengua Chinook, el potlatch, forma en la que «domina el principio de la rivalidad y del antagonismo».

\section{EL PUNTO DE PARTIDA DE SU ANÁlisis: LAS PRESTACIONES TOTALES No AGONÍSTICAS}

Ahora bien, Mauss indica claramente - y esto se silencia generalmenteque el punto de partida de su análisis se hallaba en los dones no agonísticos, a cuyo estudio no se iba a dedicar en su libro ${ }^{8}$. Pero este análisis se encuentra, por ejemplo, en las notas del Manuel d'Ethnograpbie publicado en 1947. Nos da allí como ejemplos los intercambios de bienes, de ritos, de nombres, que pueden existir entre los grupos y los individuos que componen cada una de las dos mitades en el seno de sociedades dualistas. Menciona el nombre de algunas tribus australianas o de América del Norte, pero sin hacer el análisis de la lógica particular que preside estos intercambios de dones. Trataré de completar esta carencia con lo que pude yo mismo observar en mi trabajo de campo en Nueva-Guinea acerca de la práctica del intercambio de mujeres entre los linajes y los diferentes clanes que componen la sociedad de los Baruya.

7 Mauss, Marcel, p. 151. Primera característica: «No son los individuos sino las colectividades, las que se obligan mutuamente, las que intercambian y contraen obligaciones; las personas presentes en el contrato son personas morales: clanes, tribus y familias, que se enfrentan y oponen, ya sea en grupo, cara a cara en el terreno, ya sea por mediación de su jefe, o bien mediante ambas formas a la vez". Segunda característica: "Lo que intercambian no son exclusivamente bienes y riquezas [...] cosas útiles económicamente; ante todo son cortesías, festines, ritos, servicios militares, mujeres, hijos, danzas, fiestas o ferias, de las que el mercado no es más que uno de sus aspectos, y donde la circulación de riquezas no es más que uno de los términos de un contrato más general y permanente». $Y$ finalmente: «Esas prestaciones y contraprestaciones se realizan bajo una forma más bien voluntaria, mediante presentes o regalos, a pesar de que en el fondo sean rigurosamente obligatorias, casi una guerra privada o pública».

8 Ibidem, p. 199. "EI punto de partida se halla en otro lugar. Se halla en una categoría de derechos que dejan de lado aquellos juristas y economistas que no se interesan por ella. Es el don, fenómeno complejo, sobre todo en su forma más antigua, la de la prestación total, lo que no estudiamos en esta memoria". 
El principio es bien conocido: un linaje da una mujer a otro linaje, un hombre da una de sus hermanas, real o clasificatoria, a otro hombre que le devuelve una de sus hermanas, también real o clasificatoria. Aparentemente, estos dones recíprocos deberían anular la deuda engendrada por cada uno de los dones. Pero no es así. Cuando un linaje da una mujer crea una deuda en el otro linaje y se encuentra frente a éste en relación de superioridad, pero cuando, a su vez, recibe una mujer de ese linaje, se vuelve a encontrar endeudado y en relación de inferioridad. En definitiva, al cabo de estos intercambios recíprocos cada linaje se encuentra a la vez en una posición superior e inferior frente al otro. Por lo tanto ambos se encuentran en igualdad de estatus y en relación de equilibrio entre dones y deudas. Así, los contradones no anulan las deudas creadas por los dones sino que crean otras deudas que equilibrarán a las primeras. En esta lógica, las deudas alimentan permanentemente obligaciones recíprocas que engendran flujos de servicios, de ayuda y de solidaridades. Las deudas jamás se anulan tealmente sino que lentamente se desvanecen con el correr del tiempo. Con estos ejemplos vemos que volver a dar no es devolver, cosa difícil de entender para un occidental. También se ve cuán absurdo sería entregar dos mujeres por una recibida. En última instancia, este tipo de prestaciones recíprocas conduce finalmente a la redistribución, de manera relativamente igualitaria, de los recursos de los grupos que componen la sociedad, pudiendo ser estos recursos seres humanos, mujeres y niños, o bienes, trabajos y servicios. Dentro de esta lógica una mujer vale una mujer, la muerte de un guerrero es compensada por la muerte de otro guerrero y la esfera de equivalencias entre los objetos y entre los sujetos, entre las riquezas materiales y los seres humanos, vivos o muertos, es limitada.

\section{DONES Y CONTRADONES AGONÍSTICOS, EL POTLATCH}

El potlatch, y en general los dones y contradones agonísticos, ponen en juego una lógica totalmente distinta. Mauss señala que se trata de una verdadera "guerra por las riquezas", destinada a conquistar títulos, estatus, poder, y en la que la rivalidad sobrepasa a la generosidad: es el acto de donar y de donar más que los demás lo que realmente cuenta. Como él mismo señala, se trata de otra «economía y moral del don». Partiendo de las descripciones de Boas y de autores más antiguos como los rusos y los canadienses, Mauss muestra que los potlatchs fueron practicados para legitimar la transmisión de un título ya adquirido o para hacer valer derechos para su adquisicion? ${ }^{2}$. El potlatch es, por lo tanto, un práctica que permite acceder o conservar un poder, y el medio para acceder a él es la acumulación y la redistribución de inmensas cantidades de bienes de sub-

9 Marcel Mauss tenía conocimiento de autores del siglo XIX como Krause y Jacobsen, y de los trabajos de los coetáneos de Boas, Sapir, Hill Tont, etc.

Hippania, LX/1, núm. 204 (2000) 11-26 
sistencia consumidos durante los festines, así como también la acumulación de objetos preciosos como, por ejemplo, las placas de cobre incisas. En el comienzo, varios clanes y varios jefes compiten para dar o devolver mayores cantidades, pero al final sólo uno es el vencedor, al menos provisoriamente, hasta que otro lo desafía con un potlatch más grande. Ya no estamos en la lógica de las prestaciones totales no-agonísticas, que implican una distribución relativamente igual de los recursos necesarios para la reproducción de los grupos sociales. Aquí varios grupos compiten, pero sólo uno gana. Una deuda se anula cuando se devuelve más de lo que se recibió. Se trata de donar con la intención de romper la reciprocidad de los demás. La situación ideal es que, al final, un clan haya dado tanto que nadie pueda devolver, quedando así solo, sin posibles competidores. La deuda es de nuevo esencial para la lógica del don: pues su finalidad es ser anulada con un contradon más importante. Esto genera una incesante espiral de dones y contradones que arrastra consigo a toda la sociedad.

Este es, en resumen, el análisis hecho por Mauss del potlatch. Sin embargo, en su texto aparecen mencionados hechos que él mismo no llegó a estudiar y sobre los cuales sus comentadores guardaron silencio. Escribe en una nota de pie de pagina que entre los Kwakiutl las piezas de cobre más bellas y los títulos más importantes "permanecían fijos en el interior de los clanes y de las tribus" y nunca formaban parte de los potlatch. Se conservaban en medio de los tesoros de los clanes y de las tribus mientras que las demás piezas de cobre, las más numerosas, que circulaban en los potlatch, eran de menor valor y parecían «servir de satélites para los primeros» ${ }^{10}$. Entre todos sus comentadores solamente Annette Weiner señaló la importancia de esas notas en su libro Inalienable possessions: The Paradox of keeping wbile Giving (Berkeley, 1992). Volveremos más adelante sobre este aspecto que, en principio, no planteaba aparentemente problemas pero que, de hecho, cambia el punto de vista sobre las cosas «donables" y las cosas vendibles puesto que introduce la categoría de las cosas que se deben guardar.

Antes de analizar esta categoría de objetos, volvamos a las tesis de Mauss sobre la existencia de un espíritu que está en los objetos así como sobre la distinción entre cosas y personas que caracterizaría a los universos sociales y mentales de muchas sociedades no occidentales. Esto sería la clave para poder comprender los más antiguos sistemas de derecho que existían en la antigüedad greco-latina, antes de que se elaborara la distinción entre el derecho de las personas y el derecho sobre las cosas que luego caracterizó el derecho de las sociedades occidentales'11. Estas distinciones Mauss las encontró también en los antiguos derechos de India y de China. Mauss, ya lo hemos visto, quería comprender porqué un objeto dado debía retornar a su donador o una cosa equivalente debía ser devuelta. Las nuevas investigaciones de campo sobre los concep-

10 MAuss, Marcel, p. 224, noca 1.

11 Ibidem, pp. 229 y 238. 
tos indígenas y los mecanismos de funcionamiento del kula, -el amplio sistema melanesio de intercambio de bienes preciosos que operó simétricamente al ejemplo del potlatch_-, nos permiten entender cómo una cosa dada puede ser alienada por su propietario y seguir siendo de su propiedad. Ya en 1921, admitiendo la riqueza de los datos etnográficos recogidos por Malinowski, Mauss se lamentaba que estos no mostraran suficientemente bien la práctica de los dones y contradones del kula. Escribía:

«Sociológicamente encontramos expresada una vez más una mezcla de valores, de contratos y de hombres. Desgraciadamente conocemos mal la regla de derecho que domina estas transacciones. $O$ es inconsciente y está mal formulada por la gente de Kiriwina, informantes del Sr. Malinowski, o bien, siendo claras para los Trobriandeses, una nueva encuesta sería deseable. Sólo poseemos detalles» ${ }^{12}$.

No es seguro que Mauss haya creído que las cosas estaban claras para los Trobriandeses, ya que habla al respecto de confusión de categorías. Son palabras proféticas, porque eso es precisamente lo que sucedió. Pero como ya dijimos fue necesario esperar los resultados de las nuevas investigaciones hechas a partir de la década de 1970 por Annette Weiner, Frederick Damon, Nancy Munn, Jetry Leach, John Liep y otros en una docena de sociedades todas ellas pertenecientes al Kula-ring ${ }^{13}$.

Se llegó entonces a la conclusión de que la práctica del kula descrita por Malinowski era la excepción y no la regla. En Kiriwina, la isla donde Malinowski la observó, solamente los aristócratas y los hombres de alto rango tenían derecho a consagrarse al kula y no así la gente común, a cuyo alcance no se encuentra ascender o cambiar de estatus mediante intercambios exitosos. Pero esto tampoco sucede así en otras partes. ¿Cuáles son los objetos intercambiados en el kula? Ante todo caracolas trabajadas, es decir abrillantadas, horadadas y que se presentan como collares o como pulseras. Estos objetos son clasificados en siete rangos con valores diferentes: la regla del juego establece que no se puede cambiar una pulsera por otra pulsera o un collar por otro collar, sino que se intercambia una pulsera de un rango determinado por un collar del mismo rango o la inversa. Por lo tanto, en este «juego" nunca es el mismo tipo de objeto el que ocupa el lugar del objeto dado. Es decir, no es el espíritu presente en un objeto el que impulsaría al que lo recibe como don a devolverlo a su primer propietario. En cierto modo, Mauss lo lamentaba cuando escribía:

«El Sr. Malinowski no halló una razón mítica o algún otro sentido en esta circulación de los vaygu'a", es decir los objetos preciosos que circulan en el kula. Sería muy importante fijarlos. Puesto que si la razón se encontrase en una orien-

\footnotetext{
I2 Ibidem, p. 184.

13 Véase la obra de síntesis LEACH, Jerry y Edmund (comps), The Kula. New perppectives on Massin Exchange, Cambridge, 1983.
}

Hispania, LX/1, núm. 204 (2000) 11-26 
tación cualquiera de estos objetos tendientes a volver a un punto de origen $\langle\ldots\rangle$ el hecho sería entonces prodigiosamente idéntico $\langle\ldots\rangle$ al hau maorími4.

Por desgracia no es esto lo que se encontró. De hecho Malinowski no había descubierto los dos conceptos claves que explican la práctica del kula y el hecho de que el propietario aparezca como si estuviera siempre presente en el objeto dado. Un importante descubrimento es la noción de kitoum $^{15}$. ¿Qué es un kitoum?. Se puede definir como las pertenencias de un linaje e, incluso, las de un individuo: canoas, caracolas, hojas de hachas de piedra, etc. Como kitoum, sus propietarios pueden utilizarlos en distintos contextos con diferentes usos. Pueden servir para compensar la muerte de un enemigo o como bridewealth para obtener una esposa, o intercambiarlos a cambio de una canoa grande, etc. Pero pueden también inscribirse en una de las rutas del intercambio kula, en una keda. Apenas un collar penetró en una ruta del kula — pasando de manos de su propietario a un primer receptor - se transforma en vaygu'a, es decir en un objeto que en adelante solo puede ser utilizado para los intercambios kula. Pero sigue siendo propiedad del primer donante, quién puede en cualquier momento reclamarlo al que lo posee provisoriamente y sacarlo del kula. Lo que prácticamente nunca sucede.

Sin embargo, el hecho de que teóricamente esto sea posible indica claramente la naturaleza de la relación entre el propietario, primer donante, y el objeto dado. Lo cedido al dar el objeto no es su derecho de propiedad sino el derecho de utilizarlo para hacer otros dones. Nadie, entre cuyas manos pasará el objeto precioso podrá utilizarlo como kitum y servirse de él para compensar un asesinato o para conseguir una esposa. ¿Entonces, cómo vuelve el objeto a su propietario? Nunca vuelve, lo que vuelve en lugar de un collar es una pulsera de rango equivalente cedido por alguien que fue su dueño al principio y que decidió cambiarla por el collar. La pulsera recorre entonces en sentido contrario toda la cadena de intermediarios acabando finalmente entre las manos del propietario del collar que se lo apropiará como kitum y con este acto terminará la ruta $(k e d a)$ de los intercambios.

Por lo tanto, se trata efectivamente de una tegla de derecho que explica que los bienes preciosos que circulan en los dones tengan un uso alienado y al mismo tiempo sigan siendo la propiedad inalienable del donante originario. Lo que el derecho no explica es porqué este principio se aplica a los objetos preciosos y no a los objetos sagrados que son a menudo del mismo tipo, caracolas raras o piezas de cobre muy antiguas. Vimos antes que los objetos preciosos poseen un valor imaginario que no se confunde con el trabajo necesario para descubrirlos o fabricarlos ni con su relativa escasez. Este valor imaginario traduce el hecho de que pueden ser intercambiados por la vida, que son conside-

If Mauss, Marcel, p. 179.

15 Véanse las obras citadas de Annerte Weiner y Frederick Damon. 
rados equivalentes de los seres humanos. Es ahora el momento de cruzar la línea que Mauss no cruzó.

Antes de continuar concluiré este análisis del potlatch y de las demás formas ceremoniales de contradones agonísticos, proponiendo la siguiente hipótesis que Mauss no había formulado: la hipótesis de que tales formas de competición sólo emergen si se presentan dos condiciones sociológicas e ideológicas. Por un lado, es necesario que el casamiento no se limite al intercambio directo de mujeres sino que la práctica del bridewealth, es decir, del intercambio de mujeres contra riquezas se generalice. A partir del momento en que se intercambian mujeres por riquezas, se hace posible "una verdadera economía política del parentescon. Las riquezas procuran mujeres y las mujeres procuran riquezas. Las mujeres se convierten ellas mismas en riqueza ${ }^{16}$. Por otro lado, es necesario que una parte de las posiciones de poder en la sociedad, en el campo político, sea accesible por acumulación de riquezas redistribuídas por los grupos y los individuos en competición por el poder bajo forma de dones ceremoniales. Donar siempre más, re-donar siempre más: esta es la fórmula del sistema que sin cesar lo empuja hacia sus límites ${ }^{17}$. Cuando estos dos tipos de relaciones sociales se combinan en una misma sociedad, se reunen las condiciones para que emerjan las prácticas del potlatch. Sin embargo las sociedades que tienen potlatch no son tan numerosas como lo imaginaba Mauss, quien encontraba en ellas una forma muy frecuente de economía de transición entre las sociedades primitivas con dones no antagonistas y las sociedades mercantiles. Hoy conocemos otros ejemplos de dones competitivos, en Nueva-Guinea, en Asia, etc. que Mauss no conocía, si bien no son muchos y no son parangonables con la presencia múltiple de los dones no-agonísticos.

\section{COSAS QUE NO HAY QUE VENDER, NI DAR, SINO QUE HAY QUE GUARDAR: LOS OBJETOS SAGRADOS}

Los objetos sagrados se presentan como dones que los dioses o los espíritus habrían hecho a los antepasados del hombre y que sus descendientes, los hombres actuales, no deben darlos sino conservarlos preciosamente. Es para ellos

\footnotetext{
16 Sobre el problema de la significación de las dotes que el hombre entrega a los padres de su futura esposa (bridewealth) y el de las dotes que, en ciertas civilizaciones, los padres de la mujer donan a su hija cuando ésta se traslada a casa de su marido (dowry), véase GOODY, Jack y TAMBIAH, Stanley Jeyarada (comps), Bridewealth and Doury, Cambridge, 1973, obra cuya publicación ha suscitado importanzes debates.

17 Recordemos que en dicho sistema a nadie le interesa devolver el equivalente de lo que ha recibido. El objetivo es poner al receptor del don en situación de inferioridad permanente, sustituir unas relaciones jerárquicas más o menos estables por relaciones recíprocas inestables. Tampoco aquí re-donar significa devolver, aunque la situación sea completamente distinta a la de los dones y contradones no agonísticos.
} 
tanto un elemento esencial de su identidad como una fuente de poder en la sociedad, poder que pueden ejercer sea para favorecer a los demás, sea para perjudicarlos. El objeto sagrado, a diferencia del objeto precioso, es inalienable $\mathrm{e}$ inalienado.

Mi trabajo de campo en Nueva-Guinea me dió la oportunidad de observar frecuentemente el uso de un objeto sagrado e incluso de percibir su contenido interno. Entre los Baruya, ciertos clanes poseen un kwaimatnié. Son paquetes que contienen cosas que nunca se ven y que están envueltas en tiras de corteza roja, color del sol, porque los Baruya se presentán como «hijos del sol». La palabra kwaimatnié viene de kwala, hombres y de nimatnié, hacer crecer. Los kwaimatnié son conservados secretamente en las casas de los maestros de las iniciaciones de los jóvenes y estos maestros son los representantes de los clanes que intervienen en las diferentes etapas de su iniciación, iniciación que dura más de diez años, hasta su casamiento. A los nueve años los niños son brutalmente separados de sus madres y del mundo de las mujeres y encerrados en las casas de los hombres, casas que ocupan una posición dominante en los pueblos. Allí se encuentran confrontados con diferentes objetos sagrados, flautas, rombos y los kwaimatnié. Poco a poco aprenderán que las flautas en su origen eran propiedad de las mujeres y que un antepasado de los hombres se las robó, y esas flautas contenían, y siguen conteniendo, el poder de las mujeres de engendrar, haciéndolo incluso sin los hombres. ¿Qué hay en el interior de los kwaimatnié? Tuve el privilegio, tras una estancia de varios años entre los Baruya, de que un maestro de iniciación me mostrara un día el contenido de su kwaimatnié. Vi, rodeados por tiras de corteza, una piedra negra y un hueso puntiagudo de águila, el pájaro del sol. El hombre no me dijo nada, pero yo sabía, por haber sido iniciado, que la piedra contenía el poder de Venus, una mujer Baruya, ofrecida en el pasado para apaciguar al dios de la lluvia, la serpiente pitón, maestro del trueno. En cuanto a los rombos, estos serían para los Baruya, objetos que contienen poderes de muerte, poderes para matar en la caza y en la guerra, que los Yimaka, espíritus de los bosques, habrían dado en el pasado a un ancestro de los Baruya.

Es así que en los objetos sagrados, propiedad exclusiva de ciertos clanes y utilizados exclusivamente por los hombres se encuentran reunidos dos tipos de poderes: poderes femeninos, poderes de vida de los que, en lo imaginario, los hombres expropiaron a las mujeres y poderes masculinos, poderes de muerte y de guerra recibidos directamente de los espíritus del bosque. Sin embargo, a los ojos de los Baruya, las mujeres siguen siendo propietarias de los poderes que los hombres les robaron, aunque perdieron definitivamente el uso de ellos ${ }^{18}$. Al menos, mientras los hombres sigan iniciando a los jóvenes, separándolos vio-

\footnotetext{
18 Véase GODELER, Maurice, "Du quadruple rapport entre les catégories du masculin et du féminin" en La place des femmes. Les enjeux de l'identité et de l'égalité au regard des sciences soriales, París, 1995.
} 
lentamente del mundo de las mujeres. Los hombres justifican esta violencia y esta expropiación - violencia que es un principio esencial de la organización de la sociedad baruya, uno de los fundamentos del orden- diciendo que las primeras mujeres no sabían utilizar sus poderes en beneficio de la sociedad, creando permanentemente desorden. Fue necesario que los hombres interviniesen y las desposeyeran para que el orden reinase en la sociedad y en el cosmos.

En definitiva, un objeto sagrado es un objeto material que representa lo irrepresentable, que remite a los orígenes de las cosas y es testigo de la legitimidad del orden cósmico y social que sucedió al tiempo y a los acontecimientos desde los orígenes. Un objeto sagrado no es bello como lo son los objetos de valor que se intercambian en los potlatch. Es más que hermoso, es sublime, porque pone a la humanidad en presencia de las potencias que ordenan al mundo más allá de lo visible ${ }^{19}$. Los objetos sagrados no son símbolos para los que los manejan y los exhiben, son la presencia real de las potencias que son la fuente de los poderes que encierran.

Es importante notar que en los relatos que cuentan las circunstancias en que tal o cuál objeto fue dado a los antepasados de los hombres actuales, estos antepasados aparecen a la vez más grandes y más pequeños que sus descendientes. Más grandes porque tenían la capacidad de comunicarse directamente con los dioses y de recibir sus dones, más pequeños porque en ese entonces no sabían hacer nada de lo que hacen los hombres de hoy en día - ni cazar, ni cultivar la tierra, ni casarse, ni iniciar a los niños-y que todo esto lo recibieron de los dioses. El objeto sagrado se presenta entonces como la síntesis «material» de los componentes imaginarios y simbólicos de las relaciones que organizan a las sociedades reales ${ }^{20}$. Porque entre los Baruya, en función de los ritos y en nombre de los mitos, las mujeres se encuentran realmente separadas de la propiedad de la tierra, del uso de las armas y del acceso directo a los dioses. Lo imaginario y lo simbólico aparecen entonces como momentos y componentes necesarios de la producción de estas relaciones sociales reales, relaciones de cooperación o de dominación, relaciones también de explotación.

En esta perspectiva se podría plantear la hipótesis de que el monopolio de los objetos sagrados, de los ritos y de otros medios imaginarios de acceder a las potencias que controlan el cosmos y la sociedad, debieron lógica y cronológicamente preceder la emergencia de castas o de clases, controlando también los

19 Mi análisis no trata del carácer estético o artístico de los objetos sagrados, sino de la emoción ante el carácer sagrado de esos objetos. La separación entre objeto sagrado y objeto precioso es evidente en el caso de una reliquia, que conserva un fragmento del cuerpo o del vestido de un santo. No es necesario que nada «bellow la distinga. Lo sublime no depende en absoluto del arte. Lo empleamos aquí a falta de otro término. Tal vez fuera más adecuado usar el término "numinoso», pero esta discusión nos llevatía demasiado lejos. Véase OTTo, Rudolf, Le Sacré, París, 1949.

20 Recordemos que lo imaginario está compuesto a la vez por todo lo que los hombres añaden idealmente a sus capacidades reales y por todo lo que sustraen a éstas.

Hispania, LX/1, núm. 204 (2000) 11-26 
medios materiales que producen la vida y las riquezas, la tierra y sus recursos, los individuos y su fuerza de trabajo.

No pretendo decir con ello que la religión esté en el origen de las relaciones de castas o de clases que aparecieron en numerosas regiones del mundo desde los tiempos neolíticos. Pero me parece que la religión pudo dar modelos de poder prefabricados a las sociedades en cuyo seno algunos hombres comenzaban a elevarse muy por encima de los demás y se esforzaban en legitimar, con un origen diferente, su nuevo lugar en una sociedad diferente. ¿ Acaso el Inca no se presentaba como el hijo del Sol? ¿Y el Faraón, como un dios viviente entre los hombres? Lo que hizo fue proporcionar la idea de unos seres infinitamente más poderosos que los humanos y a los que éstos están encadenados por una deuda originaria que ningún contradón puede borrar, unos seres a los que los humanos deben el respeto, la obediencia y el reconocimiento que expresan sus plegarias, ofrendas y sacrificios. La religión proporcionó la idea de relaciones jerárqucas, asimétricas, fuente a la vez de obligaciones recíprocas y de relaciones de obediencia situadas más allá de toda reciprocidad.

Para acabar con el problema de la naturaleza de los objetos sagrados es necesario ir más lejos y comprender que constituyen un testimonio extremo de la opacidad necesaria para la producción y la reproducción de las sociedades. En el objeto sagrado, los hombres que lo fabrican están simultaneamente presentes y ausentes, presentes en una forma tal que disimula el hecho de que los hombres están en el origen mismo de lo que los domina y a lo que rinden culto. Es la misma relación que los hombres tienen con el dinero cuando funciona como capital y parece ser capaz por sí mismo de autoreproducirse y de engendrar - por sí mismo- dinero.

\section{CONCLUSIÓN}

Incluso en las sociedades capitalistas más desarrolladas el «Everything for sale» según el título del libro reciente de Robert Kuttner no es cierto ${ }^{21}$. Es posible y frecuente en las sociedades democráticas comprar los votos de los electores, pero todavía no es posible comprar una constitución en un supermercado. La democracia supone y pretende que cada uno, cualquiera sea su riqueza o su pobreza, su sexo o su función, posea en igualdad con los demás una parte de la soberanía política. Una constitución democrática no es una Tabla de la Ley dada a los hombres por los dioses, es un conjunto de principios que los hombres se dan para organizar su vida común. Una constitución democrática es un bien común que no puede ser engendrado por medio de relaciones mercantiles. Por eso, en una democracia, el poder político de cada uno es un bien inalienable.

21 KUTTNER, Robert, Everything for sale: the virtues and limits of markets, Chicago, 1999. 
Vayamos más lejos. La expansión del mercado tiene sus límites y estos deberían ser claros. ¿Podemos acaso imaginar a un niño pasando un contrato con sus padres para nacer? Es una idea absurda y su absurdidad muestra que el primer lazo entre humanos, el del nacimiento, no es negociado por quienes están concernidos. Desde entonces, la vida se instituye como un don y una deuda, cualquiera sea la forma de sociedad en la que esta vida aparece. Quizá pudiéramos concluir presentando una hipótesis general sobre la naturaleza de las sociedades humanas, ya que los hombres no sólo viven en sociedad sino que producen sociedad para vivir. Me parece que para producir una sociedad es necesario combinar tres bases. Hay que dar ciertas cosas, hay que vender $o$ intercambiar otras y algunas hay que conservarias en lo posible. En nuestras sociedades vender y comprar se transformaron en actividades dominantes. Vender es operar una separación total entre las personas y las cosas, dar es siempre conservar algo de la persona en la cosa dada. Guardar es no separar las cosas de las personas porque en esa unión se afirma una identidad histórica que hay que transmitir, al menos hasta que desaparezca.

Contra los que tienen dudas quisiera decir finalmente que la antropología, es capaz de acumular descubrimientos que revelan procesos y lógicas de las cuales los propios actores no tienen conciencia o al menos una conciencia clara. Los hombres producen permanentemente dobles imaginarios de si mismos pero no pueden $\longrightarrow 0$ no quieren- reconocerse en sus dobles. De allí la importancia crítica de la antropología y de las ciencias sociales. Nuestro trabajo consiste precisamente en intentar, con otros, encontrar al hombre allí donde se halla, en el origen de si mismo. 